\title{
EFFECTIVENESS OF HANDS-OFF VERSUS HANDS-ON TECHNIQUES ON PERINEAL TRAUMA AND PERINEAL PAIN AMONG PARTURIENT MOTHERS
}

\author{
PINKIE LIZBETH THOMAS ${ }^{1}$, JAYABHARATHI ${ }^{2 *}$ \\ ${ }^{1}$ RM College of Nursing, SRM University, Kattankulathur, Kancheepuram - 603 203, Tamil Nadu, India. ${ }^{2}$ Department of Obstetrics \\ \& Gynaecology Nursing, SRM College of Nursing, SRM University, Kattankulathur, Kancheepuram - 603 203, Tamil Nadu, India. \\ Email: jayabharathimariyappan23@gmail.com
}

Received: 11 July 2016, Revised and Accepted: 15 July 2016

\section{ABSTRACT}

Objective: Labor is the process by which the fetus and the placenta leave the uterus. Delivery can occur in two ways, vaginally or by cesarean delivery. The majority of women who underwent vaginal birth may sustain perineal trauma from a spontaneous perineal tear or episiotomy or both. This study aims to assess the effectiveness of hands-off versus hands-on techniques on perineal trauma and perineal pain among parturient mothers in selected hospitals, Kerala.

Methods: The research design adopted for this study was true experimental post-test only design. The study was conducted in three hospitals at Kerala such as Karothukuzhiyil hospital, Lakshmi hospital, and Carmal hospital. The sample size was computed by power analysis based on the previous studies, and it would be a total of 90 samples, with 30 parturient mothers in each group. Simple random sampling technique (Lottery method) was adopted for the selection of parturient mothers into the study. Perineal trauma was assessed by the scale given by Royal College of Obstetrics and Gynaecology, 2001, and visual analog scale (combined numerical and categorical pain scale) was used to assess the perineal pain of parturient mothers.

Results: The results showed that there was extremely significant difference found in perineal trauma and perineal pain of parturient mothers between study Group I and study II at p=0.000 level. The mean scores of study Group I were lesser than the mean scores of study Group II. The parturient mothers in study Group I (hands-off technique) had less perineal trauma and perineal pain than study Group II (hands-on technique).

Conclusion: Different perineal techniques and interventions such as hands-on technique, hands-off technique, perineal massage, and warm compresses can be widely used by midwives and birth attendants to prevent perineal trauma during labor.

Keywords: Hands-off technique, Hands-on technique, Perineal trauma, Perineal pain.

(C) 2016 The Authors. Published by Innovare Academic Sciences Pvt Ltd. This is an open access article under the CC BY license (http://creativecommons. org/licenses/by/4. 0/) DOI: http://dx.doi.org/10.22159/ajpcr.2016.v9i6.14045

\section{INTRODUCTION}

Labor is the process by which the fetus and the placenta leave the uterus. Delivery can occur in two ways, vaginally or by cesarean delivery. Labor occurs in three stages and can actually begin weeks before a woman delivers her infant. The first stage begins with the woman's first contractions and continues until the cervix is fully dilated $(10 \mathrm{~cm})$, it has stretched its maximum to prepare for birth. The second stage is the active stage, in which the pregnant woman begins to push downward. It begins with complete dilation of the cervix and ends with the actual birth. The third stage or placental stage begins with the birth and ends with the completed delivery of the placenta and afterbirth [1]

Every year millions of women worldwide sustain trauma to the perineum when giving birth. Around $6 \%$ of these women will have short-term wound complications such as infection and dehiscence. Some are also at risk of long-term problems such as dyspareunia, pain, urinary and fecal incontinence, pelvic organ prolapse, and psychosocial problems. Correct assessment and repair of this trauma are, therefore, essential to help reduce long-term complications. The focus is mainly on the management of childbirth-related perineal trauma such as first and second degree perineal trauma and injury to and sphincter complex $[2,3]$.

The majority of women who underwent vaginal birth may sustain perineal trauma from a spontaneous perineal tear or episiotomy or both. An overall perineal trauma rate of $85 \%$ was reported by Albers et al. (2005). Perineal trauma is highly associated with perineal pain and dyspareunia, with perineal pain being one of the most commonly reported symptoms in the postnatal period. Other risk factors for perineal pain include mode of birth and primiparity. These factors are all highly inter-related, so care has to be taken when reporting on the independent effects of each. There is some evidence to suggest that the severity of the perineal injury is linked to the severity of perineal pain (Macarthur and Macarthur, 2004) [4].

Perineal wounds requiring medical care and pain management may result in longer hospital stays, causing further stress on women, their families, and the health-care system. Women discharged early also require extra attention from community midwives for ongoing management of wounds. Women suffering longer-term postpartum complications are reluctant to seek help, resulting in silent suffering of treatable conditions [5].

Perineal pain is a common symptom among mothers that may occur immediately following the birth and persist beyond the postnatal period. A survey conducted with 2400 women in the United States showed that among 1656 women who underwent vaginal delivery, 40\% reported perineal pain in the first 2 months following the delivery. At or after six months, some of them still reported pain in the perineum as a persistent problem. In general, the occurrence and intensity of perineal pain are related to the severity of injury in this region [6].

Mccandlish and Petrocnik conducted a systematic review on all available literature that compares the hands-on and hands-poised techniques of perineal management during the second stage of labor. The hands-poised technique appeared to cause less perineal trauma and reduced rates of episiotomy. The hands-on technique resulted in increased perineal pain after birth and higher rates of postpartum hemorrhage. Evidence would suggest that the hands-poised technique is a safe and recommended technique for perineal management and 
discussions of such a technique should be included in all midwifery education and training programs. Until, there is conclusive evidence, the choice of the hands-on or hands-poised technique will ultimately be determined by the clinical judgment of the individual midwife at the time of birth. Further research is recommended. Thorough conclusions could significantly impact on reducing postpartum morbidity and improving women's sexual health and well-being in the long-term, throughout the world [7].

Berridgeet conducted a study on the effect of two methods of perineal management used during spontaneous delivery. Questionnaires were completed by $97 \%$ of women at 10 days after birth. 910 (34.1\%) women in the "hands-poised" group reported pain in the previous 24 hrs compared with $823(31.1 \%)$ in the "hands-on" group (risk ratio [RR] 1-10, 95\% confidence interval [CI] 1.01-1.18: "Absolute difference 3\%" $0.5-5 \%, \mathrm{p}=0.02$ ). The rate of episiotomy was significantly lower in the "hands-poised" group (RR 0.79, 95\% CI 0.65-0.96, p=0.008) but the rate of manual removal of placenta was significantly higher (RR 1-69, 95\% CI 1.02-2.78; $\mathrm{p}=0.008$ ). There were no other statistically significant differences detected between the two methods. The reduction in pain observed in the "hands-on" group was statistically significant and the difference detected potentially affects a substantial number of women. These results provide evidence to enable individual women and health professionals to decide which perineal vaginal delivery management is preferable [8].

Vaginal births are often associated with some form of trauma to the genital tract, which can sometimes be associated with significant short- and long-term problems for the women. It is especially the third- and fourth-degree tears that affect the anal sphincter or mucosa which can cause the most problems. Perineal trauma can occur spontaneously or result from a surgical incision of the perineum, called episiotomy. Different perineal techniques and interventions are being used to slow down the birth, and allow the perineum to stretch slowly to prevent perineal injury. Perineal massage, warm compresses, and different perineal management techniques are widely used by midwives and birth attendants [9].

The aim of the present study is to assess the effectiveness of handsoff versus hands-on techniques on perineal trauma and perineal pain among parturient mothers in selected hospitals, Kerala.

\section{METHODS}

The research design adopted in this study was true experimental post-test only design. The study was conducted in three hospitals at Kerala such as Karothukuzhiyil Hospital, Lakshmi Hospital, and Carmal Hospital. These hospitals are speciality in obstetrics and gynecology. More than 100 deliveries will be conducted in a month. The setting was chosen on the basis of feasibility in terms of availability of adequate samples and the co-operation extended by the management. There are more than 10 mothers were admitted per day in each hospital. The sample size was computed by power analysis based on the previous studies, and it would be a total of 90 samples, with 30 parturient mothers in each group. From each setting, the investigator selected 30 samples (Karothukuzhiyil hospital as study Group I, Lakshmi hospital as study Group II, and Carmal hospital as control group) to attain 90 samples within the stipulated period. Simple random sampling technique $[10,11]$ (Lottery method) was adopted for the selection of parturient mothers into the study. The inclusion criteria for the study includes: (a) Mothers who were in the II stage of labor, (b) mothers who were second gravid, (c) mothers whose estimated fetal weight ranged from 2.5 to $3 \mathrm{~kg}$ by ultrasonography, and (d) mothers who were at term with cephalic presentation (left occiput anterior [LOA] and right occiput anterior [ROA]). The exclusion criteria includes: (a) Mothers who were less than 18 years of age and more than 30 years of age, (b) mothers who were diagnosed as high risk and had complications such as pregnancy-induced hypertension, anemia, gestational diabetes mellitus, and multiple pregnancy, (c) mothers who had squatting position during second stage of labor, (d) women who had complicated labor-like obstructed labor and shoulder dystocia, and (e) mothers who had other gynecological disorders such as anorectal malformations.

\section{DEVELOPMENT AND DESCRIPTION OF TOOL}

The tool consists of three parts.

\section{Section A}

A structured questionnaire was used to assess the demographic variables such as age, educational status, religion, occupation, duration of marriage, gestational weeks, and fetal position.

\section{Section B}

This section comprised tools for assessing the perineal trauma according to the scale given by Royal College of Obstetrics and Gynaecology, 2001. This classification was found more feasible and appropriate for the majority of studies related to perineal trauma. The scores are interpreted as mild injury, moderate injury, and severe injury.

\section{Section C}

This section comprised visual analog scale (combined numerical and categorical pain scale) to assess perineal pain of parturient mothers. The perineal pain was assessed from first postnatal day to third postnatal day. The scores are interpreted as no pain, mild pain, moderate pain, and severe pain.

\section{DESCRIPTION OF THE INTERVENTION}

The investigator has given hands-off technique to the parturient mothers in study Group I and hands-on technique to the parturient mothers in study Group II, and hospital routine measures were followed for the parturient mothers in the control group.

\section{Study Group I (hands-off technique)}

It refers to the technique, in which the investigator only observes the successive movements of restitution, external rotation, delivery of the shoulders, and the remainder of the body during of the second stage of labor.

\section{Study Group II (hands-on technique)}

It refers to the technique, in which the investigator places the index, ring and little fingers of the left hand close together on the Fetus's occiput with the palm turned toward the anterior region of the perineum during of the second stage of labor. In this manner, expulsion is controlled by maintaining the flexion of the head protecting the anterior region of the perineum, providing support to the perineal muscles.

\section{RELIABILLITY OF THE TOOL}

Reliability of the tool was established by test-retest method. The $r$ value was $r=0.82$ for perineal trauma and $r=0.76$ for perineal pain. Hence, it was considered and feasible for proceeding with the main study.

\section{ETHICAL CONSIDERATIONS}

Formal approval was obtained from the Institutional Review Board and Institutional Ethical Committee of SRM University, Kattankulathur, Chennai, Tamil Nadu, India. To execute the study, the researcher obtained official written permission from each of the three individual hospitals (Karothukuzhiyil Hospital, Lakshmi Hospital, and Carmal Hospital) at Kerala. Potential benefits and risks were explained to the women in labor by the investigator. Informed consent was obtained from the mothers after explaining the study purpose, type of data, nature of commitments, participation, and procedure. Confidentiality and anonymity pledge were ensured.

\section{RESULTS}

The data were analyzed using both descriptive and inferential statistics. 
Regarding the demographic variables of parturient mothers in study Group I, most of them $12(40.00 \%)$ were in the age between 23 and 26 years, most of them 13 (43.33\%) belongs to Muslim religion and $8(26.67 \%)$ was Hindu religion. Regarding the educational status, $12(40.00 \%)$ were graduate, and only $1(3.33 \%)$ completed middle school certificate. Considering the occupation, majority 16 (53.33\%) were employed and only $1(3.33 \%)$ was shop owner. Regarding duration of marriage, $21(70.00 \%)$ were above 3 years and $9(30.00 \%)$ were in between 1 and 3 years. Considering gestational weeks, $15(50.00 \%)$ were in 39 weeks and $7(23.33 \%)$ were in 40 weeks. Considering the fetal position, $23(76.67 \%)$ had LOA and 7 (23.33\%) had ROA.

Regarding the demographic variables of parturient mothers in study Group II, most of them 15 (50.00\%) were in between above 30 years and $2(6.67 \%)$ were in the $18-22$ years. Considering the religion, most of them $13(43.33 \%)$ belonged to Muslim religion and 7 (23.33\%) were Hindu religion. Regarding the educational status, $12(40.00 \%)$ were in high school and post high school and only $6(20.00 \%)$ only were graduate. Regarding the occupation, majority 14 (46.67\%) were unemployed and $8(26.67 \%)$ were semi-profession and profession. Regarding duration of marriage, $18(60.00 \%)$ were above 3 years and $12(40.00 \%)$ were in between 1 and 3 years. Considering gestational weeks, $13(43.33 \%)$ were in 39 weeks and $5(16.67 \%)$ were in 38 weeks. Considering the fetal position, $18(60.00 \%)$ had LOA and $12(40.00 \%)$ had ROA.

Regarding the demographic variables of parturient mothers in the control group, most of them $15(50.00 \%)$ were in the age between 27 and 30 years most of them $15(50.00 \%)$ belonged to Muslim religion and $7(23.33 \%)$ was Hindu religion. Regarding the educational status, $16(53.33 \%)$ were post high school and only $3(10.00 \%)$ were high school certificate. Considering the occupation, majority 19 (63.33\%) were unemployed and $4(13.33 \%)$ were semi-profession. Regarding duration of marriage, $18(60.00 \%)$ were above 3 years and $12(40.00 \%)$ were in between 1 and 3 years. Considering gestational weeks, $13(43.33 \%)$ were in 39 weeks and $5(16.67 \%)$ were in 38 weeks. Considering fetal position, $24(80.00 \%)$ had LOA, and $6(20.00 \%)$ had ROA.

Regarding the perineal trauma of parturient mothers, majority $23(76.7 \%)$ of parturient mothers in study Group I had mild trauma and only $3(10.0 \%)$ had moderate trauma. In study Group II, majority $25(83.3 \%)$ had moderate trauma and only $5(16.7 \%)$ had mild trauma. In control group, majority $17(56.7 \%)$ had moderate trauma and only $2(6.7 \%)$ had mild trauma.

The analysis depicted that there was extremely significant difference found between study Group I and study Group II at $p=0.000$ level. The mean scores of study Group I were lesser than the mean scores of study Group II (Table 1).

The analysis revealed that there was extremely significant difference found between study Group I and control group at $\mathrm{p}=0.000$ level. The mean scores of study Group I were lesser than the mean scores of the control group (Table 2).

The analysis revealed that there was extremely significant difference found between study Group II and control group at $p=0.000$ level. The mean scores of study Group II were lesser than the mean scores of the control group (Table 3).

Regarding the perineal pain of parturient mothers in study Group I, study Group II, and control group, majority 25 (83.3\%) of parturient in study Group I had mild pain and only $5(16.7 \%)$ had moderate pain. In study Group II, majority 17 (56.7\%) had mild pain and 13 (43.3\%) had moderate pain. In control group, majority $25(83.3 \%)$ had severe pain and $5(16.7 \%)$ had moderate pain.
The analysis depicted that there was extremely significant difference found between study Group I and study Group II at $p=0.000$ level. The mean scores of study Group I were lesser than the mean scores of study Group II (Table 4).

The analysis depicted that there was extremely significant difference found between study Group I and control group at $p=0.000$ level. The mean scores of study Group I were lesser than the mean scores of the control group (Table 5).

The analysis depicted that there was extremely significant difference found between study group II and control group at $p=0.000$ level. The mean scores of study Group II were lesser than the mean scores of the control group (Table 6).

Table 1: Comparison of the post-test level of perineal trauma of parturient mothers between study Group I and study Group II $(\mathrm{N}=60)$

\begin{tabular}{lllll}
\hline $\begin{array}{l}\text { Perineal } \\
\text { trauma }\end{array}$ & Mean & $\begin{array}{l}\text { Standard } \\
\text { deviation }\end{array}$ & $\begin{array}{l}\text { Standard } \\
\text { error mean }\end{array}$ & $\begin{array}{l}\text { Student's } \\
\text { independent } \\
\text { t-test }\end{array}$ \\
\hline $\begin{array}{l}\text { Study Group I } \\
\text { (n=30) }\end{array}$ & 1.967 & 0.490 & 0.089 & $\begin{array}{l}\mathrm{t}=-9.464 \\
\mathrm{p}=0.000\end{array}$ \\
$\begin{array}{l}\text { Study Group II } \\
\text { (n=30) }\end{array}$ & 3.300 & 0.596 & 0.109 & \\
\hline
\end{tabular}

Table 2: Comparison of the post-test level of perineal trauma of parturient mothers between study Group I and control group $(\mathrm{N}=60)$

\begin{tabular}{lllll}
\hline $\begin{array}{l}\text { Perineal } \\
\text { trauma }\end{array}$ & Mean & $\begin{array}{l}\text { Standard } \\
\text { deviation }\end{array}$ & $\begin{array}{l}\text { Standard } \\
\text { error mean }\end{array}$ & $\begin{array}{l}\text { Student's } \\
\text { independent } \\
\text { t-test }\end{array}$ \\
\hline $\begin{array}{l}\text { Study GroupI } \\
(\mathrm{n}=30)\end{array}$ & 1.967 & 0.490 & 0.089 & $\mathrm{t}=-16.501$ \\
$\begin{array}{l}\text { Control group } \\
(\mathrm{n}=30)\end{array}$ & 3.833 & 0.379 & 0.069 & $\mathrm{p}=000$ \\
\hline
\end{tabular}

Table 3: Comparison of post-test level of perineal trauma of parturient mothers between study Group II and control group $(\mathrm{N}=60)$

\begin{tabular}{lllll}
\hline $\begin{array}{l}\text { Perineal } \\
\text { trauma }\end{array}$ & Mean & $\begin{array}{l}\text { Standard } \\
\text { deviation }\end{array}$ & $\begin{array}{l}\text { Standard } \\
\text { error mean }\end{array}$ & $\begin{array}{l}\text { Student's } \\
\text { independent } \\
\text { t-test }\end{array}$ \\
\hline $\begin{array}{l}\text { Study Group II } \\
(\mathrm{n}=30)\end{array}$ & 3.300 & 0.596 & 0.109 & $\begin{array}{l}\mathrm{t}=-4.136 \\
\mathrm{p}=0.000\end{array}$ \\
$\begin{array}{l}\text { Control group } \\
(\mathrm{n}=30)\end{array}$ & 3.833 & 0.379 & 0.069 & \\
\hline
\end{tabular}

Table 4: Comparison of post-test level of perineal pain of parturient mothers between study Group I and study Group II $(\mathrm{N}=60)$

\begin{tabular}{lllll}
\hline $\begin{array}{l}\text { Perineal } \\
\text { pain }\end{array}$ & Mean & $\begin{array}{l}\text { Standard } \\
\text { deviation }\end{array}$ & $\begin{array}{l}\text { Standard } \\
\text { error } \\
\text { mean }\end{array}$ & $\begin{array}{l}\text { Student's } \\
\text { independent } \\
\text { t-test }\end{array}$ \\
\hline $\begin{array}{l}\text { Study Group I } \\
(\mathrm{n}=30)\end{array}$ & 2.167 & 0.379 & 0.069 & $\begin{array}{l}\mathrm{t}=-11.001 \\
\mathrm{p}=0.000\end{array}$ \\
$\begin{array}{l}\text { Studygroup II } \\
(\mathrm{n}=30)\end{array}$ & 3.433 & 0.504 & 0.092 & \\
\hline
\end{tabular}


Table 5: Comparison of the post-test level of perineal pain of parturient mothers between study Group I and control group $(\mathrm{N}=60)$

\begin{tabular}{lllll}
\hline $\begin{array}{l}\text { Perineal } \\
\text { pain }\end{array}$ & Mean & $\begin{array}{l}\text { Standard } \\
\text { deviation }\end{array}$ & $\begin{array}{l}\text { Standard } \\
\text { error } \\
\text { mean }\end{array}$ & $\begin{array}{l}\text { Student's } \\
\text { independent } \\
\text { t-test }\end{array}$ \\
\hline $\begin{array}{l}\text { Study Group I } \\
(\mathrm{n}=30)\end{array}$ & 2.167 & 0.379 & 0.069 & $\begin{array}{l}\mathrm{t}=-17.029 \\
\mathrm{p}=0.000\end{array}$ \\
$\begin{array}{l}\text { Control group } \\
(\mathrm{n}=30)\end{array}$ & 3.833 & 0.371 & 0.062 & \\
\hline
\end{tabular}

Table 6: Comparison of the post-test level of perineal pain of parturient mothers between study Group II and control group $(\mathrm{N}=60)$

\begin{tabular}{lllll}
\hline Perineal pain & Mean & $\begin{array}{l}\text { Standard } \\
\text { deviation }\end{array}$ & $\begin{array}{l}\text { Standard } \\
\text { error } \\
\text { mean }\end{array}$ & $\begin{array}{l}\text { Student's } \\
\text { independent } \\
\text { t-test }\end{array}$ \\
\hline $\begin{array}{l}\text { Study Group II } \\
(\mathrm{n}=30)\end{array}$ & 3.433 & 0.504 & 0.092 & $\begin{array}{l}\mathrm{t}=-3.474 \\
\mathrm{p}=0.000\end{array}$ \\
$\begin{array}{l}\text { Control group } \\
(\mathrm{n}=30)\end{array}$ & 3.833 & 0.371 & 0.062 & \\
\hline
\end{tabular}

\section{DISCUSSION}

Women suffering with perineal trauma, pain, and edema are the most crucial concerns in first few days following childbirth. These women have an initial decrease in mobility and the ability to perform daily activities. Difficulty in sitting as a result of perineal pain may impede the initiation of breastfeeding and affect mother-infant bonding. These restrictions add pressure to new mothers attempting to socialize into the role of motherhood. Perineal trauma contributes to urinary and fecal incontinence and sexual dysfunction. Up to $60 \%$ of women with perineal trauma report pain during intercourse three months after birth, with 30\% experiencing pain at six months [12].

The current study results showed that there was extremely significant difference found in perineal trauma and perineal pain of parturient mothers between study Group I and study Group II at $\mathrm{p}=0.000$ level. The mean scores of study Group I were lesser than the mean scores of study Group II. There was no association found between the posttest level of perineal trauma and perineal pain of parturient mothers with the demographic variables such as age, religion, educational qualification, occupation, duration of the marriage, gestational weeks, and fetal position.

Perineal trauma during childbirth can occur either spontaneously as a laceration or intentionally as an episiotomy. Rates of trauma are estimated to be between $30 \%$ and $85 \%$ of childbearing women and can lead to significant short- and long-term morbidities such as perineal pain, incontinence, and sexual problems. Research that sheds light on the efficacy of methods for reducing perineal trauma can assist midwives to improve their practice to preserve perineal integrity. This inquiry reviews the current literature on this topic to identify which methods are supported by scientific evidence. In addition, associations are identified from descriptive studies of nursemidwifery practice to identify areas that should be targeted for future research [13].

The present study results are consistent with the study done by Rezaei et al., on comparison of the "hands-off" and "hands-on" methods to reduce perineal lacerations: A randomized clinical trial. Study participants included 600 nulliparous expectant mothers, who were divided equally between the "hands-off" and "hands-on" groups ( $\mathrm{n}=300$ per group). A total of 147 (49\%) women in the "hands- on" and 143 women (47.7\%) in the "hand-off" groups encountered perineal trauma $(\mathrm{p}=0.74)$. In the "hands-on" group, 8 women $(2.7 \%)$ experienced a third-degree trauma compared with $(0.3 \%)$ that in the "hands-off" method ( $\mathrm{p}=0.1)$. Episiotomy was performed on 38 women (12.7\%) from the "hands-on" and 17 (5.7\%) women from the "hands-off" ( $p=0.003)$ groups. In addition, 28 women $(9.3 \%)$ from the "hands-on" group and 47 women $(15.7 \%)$ from the "hands-off" group experienced periurethral tears $(p=0.01)$ that did not need mending. Application of the "hands-off" method for vaginal delivery has a positive effect on the mother's health because of the reduction of episiotomy and third-degree tearing. Therefore, it is concluded that the "hands-off" method offers a safer alternative for perineal control during labor [14].

Many women suffer from perineal trauma during the normal vaginal delivery. Perineal trauma is mainly associated with pain and complications after the childbirth. Perineal management techniques can play a significant role in perineal trauma reduction. Perineal traumas particularly caused by following vaginal delivery are associated with short- and long-term morbidity for women. Therefore, interventions that increase the probability of intact perineum are necessary [15].

\section{CONCLUSION}

The present study results showed that there was a significant difference found in the perineal trauma and perineal pain of parturient mothers between the study Group I and study Group II at $\mathrm{p}=0.000$ level. The parturient mothers in study Group I (hands-off technique) had less perineal trauma and perineal pain than study Group II (hands-on technique). Vaginal births are often associated with some form of trauma to the genital tract, which can sometimes be associated with the significant short- and long-term problems for the woman. Different perineal techniques and interventions such as hands-on technique, hands-off technique, perineal massage, and warm compresses can be widely used by midwives and birth attendants to prevent perineal trauma.

\section{REFERENCES}

1. US Department of Health and Human Services National Institutes of Health. Available from: https://www.nichd.nih.gov.

2. Sherburn M. Managing perineal trauma after childbirth. BMJ 2014;349 Available from: http://www.dx.doi.org/10.1136/bmj.g6829. [Last published on 2014 Nov 26].

3. Khaled MK. Professor of obstetrics and gynaecology, managing perineal trauma after childbirth. BMJ 2014;349. Available from: http:// www.dx.doi.org/10.1136/bmj.g6829. [Last published on 2014 Nov 26].

4. The Royal College of Midwives, Evidence Based Guidelines for Midwifery-Led Care in Labour (OThe Royal College of Midwives; 2012. Available from: https://www.rcm. org.uk.

5. Creswell JW, Hooper V, Kohn ML, Atkinson LJ. Perineal trauma and childbirth. The Complete Recovery Room Book. IIII ${ }^{\text {rd }}$ ed. New York: Oxford University Press; 2004. p. 28-31.

6. Rowlands IJ, Redshaw M. Mode of birth and women's psychological and physical wellbeing in the postnatal period. BMC Pregnancy Childbirth 2012;12:138.

7. McCandlish, Petrocnik P. Midwifery. Available from: http:// www.elsevier.com/midw, http://www.dx.doi.org/10.1016/j. midw.2014.10.004.

8. Berridgeet G. A study on effect of two methods of perineal management. J Res Med Sci 2011;16(8):1040-6.

9. Aasheim V, Vika NA, Lukasse M, Pregnancy and child birth group, cochrane, trusted evidence. Informed Decisions, Better Health. Available from: http://www.cochrane.org. [Last accessed on 2011 Dec 07].

10. Polit DF, Hungler BP. Sampling design. Nursing Research - Principles and Method. VI ${ }^{\text {th }}$ ed. Philadelphia, PA: Lippincott; 1999. p. 279-89.

11. Sharma SK. Types of research design. Nursing and Statistics. St. Louis: Elsevier; 2011. p. 99-110.

12. Muda SM. Maintaining Women's Perinealintegrity: Participatory Action Research Study, PhD Thesis, Southern Cross University, Lismore, NSW. Copyright SM Muda, 2014. 
13. Journal of Midwifery and Women's Health. Available from: http:// www.institute ofmidwifery.org.

14. Rezaei R, Saatsaz S, Chan YH, Nia HS. A comparison of the "hands-off" and "hands-on" methods to reduce perineal lacerations: A randomised clinical trial. J Obstet Gynaecol India 2014;64(6):425-9.

15. Fahami F, Shokoohi Z, Kianpour M. The effects of perineal management techniques on labor complications. Iran J Nurs Midwifery Res 2012;17(1):52-7. 